\title{
Analisa Rekonfigurasi Jaringan Distribusi 20 kV Pada Penyulang Berawa Untuk Menurunkan Losses dan Drop Tegangan Penyaluran Tenaga Listrik
}

\author{
I Gusti Nyoman Indra Wiguna ${ }^{[1]}$, I Gede Dyana Arjana ${ }^{[2]}$, Tjok. Gede Indra $P^{[3]}$ \\ Jurusan Teknik Elektro, Fakultas Teknik, Universitas Udayana \\ Email: gustinyomanindrawiguna@gmail.com
}

\begin{abstract}
Abstrak
Beban puncak Penyulang Berawa sangatlah tinggi melebihi batas maksimum yang ditetapkan PLN menyebabkan nilai Losses dan drop tegangan tinggi, sehingga dilakukan rekonfigurasi Penyulang memalui LBS Canggu Club dan LBS Damai Residance, menggunakan 3 lokasi pemindahan beban. Arus sebelum direkonfigurasi pada Penyulang Berawa sebesar 242A menjadi 180,2A, Sedangkan Penyulang Bumbak sebelumnya 82A menjadi 144,7A. losses penghantar Penyulang Bumbak sebelumnya $5,2 \mathrm{~kW}$ menjadi $22,15 \mathrm{~kW}$, sedangkan Penyulang Berawa sebelumnya $117,1 \mathrm{~kW}$ menjadi $55,11 \mathrm{~kW}$ setelah di rekonfigurasi,drop tegangan Penyulang Bumbak sebelumnya 102kVA menjadi 24kVA, Sedangkan Penyulang Berawa sebelumnya $775,4 \mathrm{kVA}$ menjadi $490,2 \mathrm{kVA}$ setelah di rekonfigurasi. Perubahan beban disebabkan perubahan beban dan panjang saluran setelah direkonfigurasi.
\end{abstract}

Kata Kunci : Rekonfigurasi, LBS, Losses dan Drop Tegangan

\begin{abstract}
Peak load on Berawa Feeder is very high exceeding the maximum limit set by PLN which causes Losses and high voltage drop values, so reconfiguration of Repeater via LBS Canggu Club and LBS Damai Residance is carried out, using 3 distribution points. The flow before being reconfigured in the Swamp Feeder was 242A to 180.2A, while the previous Bumbak Feeder was $82 \mathrm{~A}$ to 144.7A. losses previous deliveries of Bumbak Feederwere 5.2kW to 22.15kW, while previous Berawa Berulang was $117.1 \mathrm{~kW}$ to $55.11 \mathrm{~kW}$, drop the previous Bumbak Feeder voltagewas 102kVA to 24kVA, whereas the previous Swamp Feeder was 775.4kVA to 490.2kVA. Load surges and decreases are caused by changes in load and channel length after being reconfigured.
\end{abstract}

Keywords : Rekonfigurasi, LBS, Losses dan Drop Tegangan

\section{PENDAHULUAN}

Data beban puncak PT. PLN (persero) APD Bali pada Penyulang Berawa sudah mencapai $81 \%$ pada tanggal 23 maret 2017 dengan beban sebesar 242 A dimana pemebebanan maksimal yang dianjurkan oleh PLN sebesar 80\% (240 A), rata-rata pembebanan Penyulang Berawa sebesar 70,3\% [1],maka dilakukan pemerataan beban dengan pemindahan sebagian beban penyulang berawa ke beban penyulang yang lebih rendah untuk menurunkan losses dan Drop tegangan.

Rekonfigurasi jaringan merupakan suatu usaha merubah bentuk konfigurasi jaringan distribusi dengan mengoprasikan pensaklaran terkontrol jarak jauh (switching remotely controlled) pada LBS jaringan distribusi tanpa menimbulkan akibat yang beresiko dalam operasi sistem jaringan distribusi secara keseluruhan [2]dengan menentukan nilai losses dan drop tegangan terkecil pada titik pemindahan beban rekonfigurasi penyulang. Penyulang Berawa akan dipindahkan sebagian bebannya ke Penyulang Bumbak yang terhubung terhubung dengan LBS Canggu Club atau LBS Damai Residance, sebagian beban lainnya akan oleh Penyulang Batu Belig yang terhubung dengan LBS Kayu 
Putih, Penyulang Berawa dan Penyulang Batu Belig disuplai oleh Transformator 2 pada Gardu Induk Padang Sambian.

\section{KAJIAN PUSTAKA}

Rekonfigurasi jaringan distribusi merupakan upaya yang dilakukan untuk menyalurkan tenaga listrik yang maksimal dalam mempermudah melokalisir jaringan apabila terjadi suatu gangguan ke penyulang lain. Rekonfigurasi dilakukan pada jaringan distribusi yang mengalami overload beban, untuk mengatasi masalah pada sistem jaringan tersebut dengan menentukan lokasi pemindahan bebanrekonfigurasi berdasarkan losses dan drop tegangan terkecil [3]

A. Drop Tegangan

Standar Drop tengangan yang ditentukan oleh PLN (SPLN) adalah maksimum sebesar $10 \%$. Tegangan jatuh pada jaringan disebabkan adanya rugi tegangan akibat hambatan listrik $(R)$ dan reaktansi $(X)$. Jatuh tegangan phasor $\mathrm{Vd}$ pada suatu penghantar yang mempunyai impedansi (Z) dan membawa arus (I) dapat dijabarkan dengan rumus [4]

$(\Delta V)=\mathrm{I}(\mathrm{R} \cdot \cos \varphi+\mathrm{X} \cdot \sin \varphi) \mathrm{X} \mathrm{L}$

Keterangan :

$\Delta V=$ Drop Tegangan

$$
\begin{aligned}
I & =\text { Arus beban ( Ampere }) \\
R & =\text { Tahanan rangkaian }(\text { Ohm }) \\
X & =\text { Reaktansi rangkaian }(\text { Ohm })
\end{aligned}
$$

B. Losses penghantar

Losses atau rugi-rugi daya yaitu kehilangan daya listrik saat penyaluran daya dari sumber ke konsumen [4] nilai losses dapat dirumuskan dengan:

$\Delta V=\mathrm{I} \times(\mathrm{r} \cdot \operatorname{Cos} \theta+\mathrm{x} \cdot \operatorname{Sin} \theta) \times \mathrm{L}$

$\Delta P=\mathrm{I}^{2} \times \mathrm{r} \times \mathrm{L}$

Keterangan:

$\Delta P \quad=$ losses penghantar

$\mathrm{I}=$ Arusnya yang mengalir pada penghantar

$r=$ Tahanan pada penghantar per $\mathrm{km}$

$\mathrm{x}=$ Reaktansi pada penghantar per $\mathrm{km}$
Cos $\mathrm{Q}=$ Faktor daya beban

\section{METODE PENELITIAN}

Penelitian ini dilakukan di Penyulang Berawa daerah Berawa, Badung, Bali. Data yang digunakan pada penelitian kali ini hasil primer dari Pengukuran beban Penyulang Berawa pada PT. PLN(Persero) Area Bali Selatan. Penelitian kali ini dilakukan dengan mebandingkan losses dan drop tegangan terkecil menggunakan 3 metode untuk menentukan titik perpotongan rekonfigurasi jaringan.

Tiga lokasi pemindahan beban yang berbeda akan dibandingan untuk menentukan titik perpotongan rekonfigurasi dan melihat pengaruh rekonfigurasi dalam jangka panjang. [2]

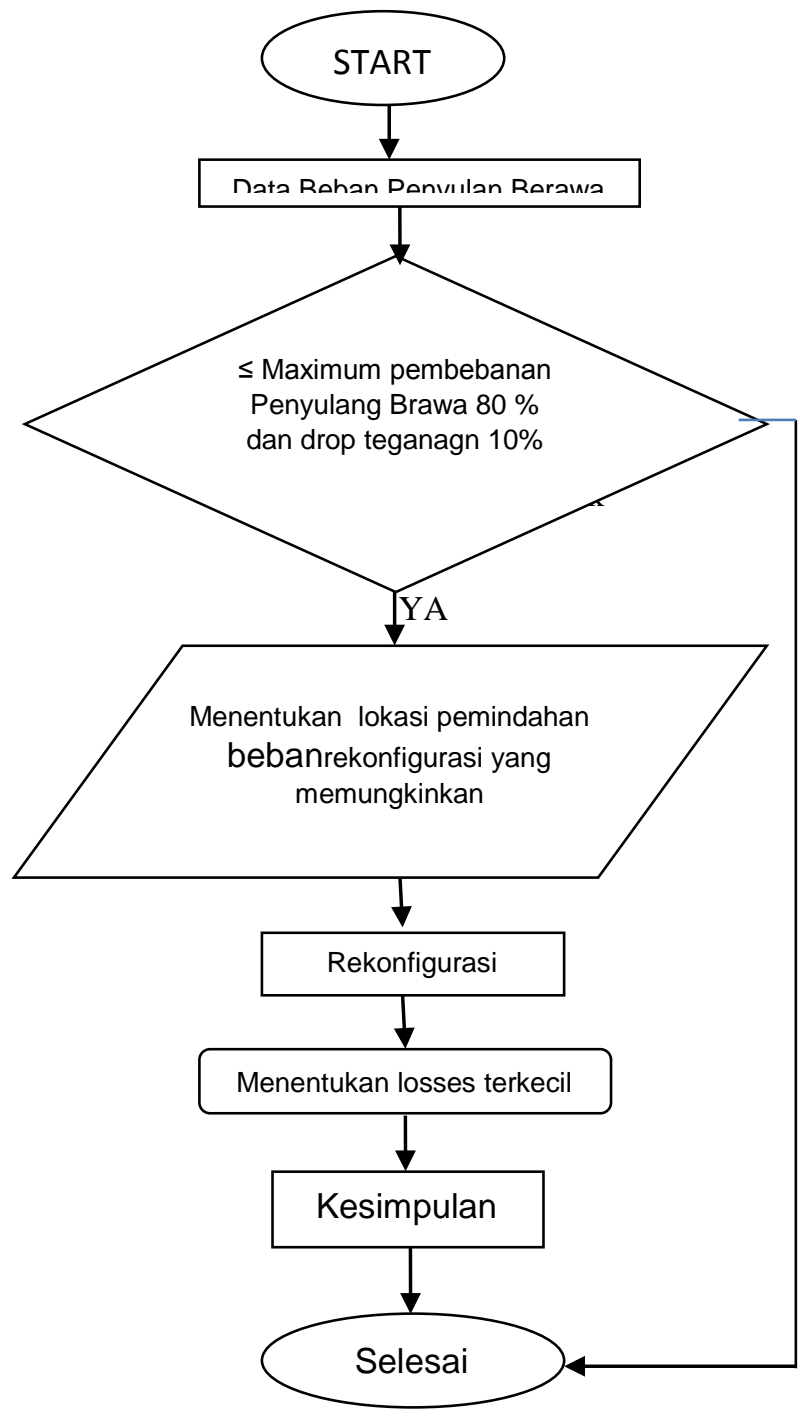


Gambar 1 Skema Metode Aliran Daya Newton Rapshon

\section{HASIL PEMBAHASAN}

\section{A. Simulasi rekonfigurasiPenyulang \\ Berawa}

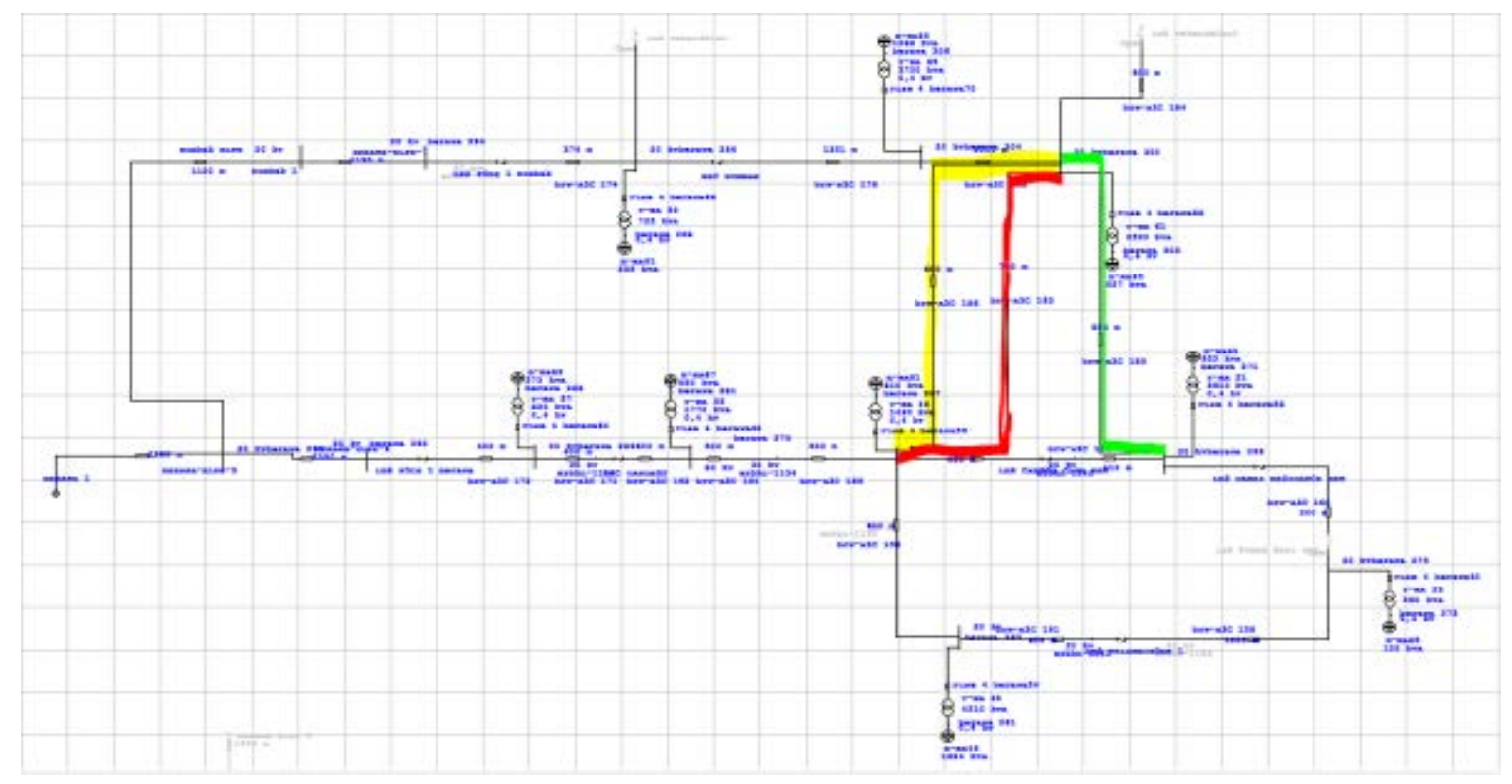

Gambar 2 simulasi etap penyulang berawa

Simulasi rekonfigurasi Penyulang Berawa ini menggunakan aplikasi Etap untuk mementukan drop tegangan, losses, dan titik rekonfigurasi yang paling effisien. menggunakan tiga sample, melalui LBS Canggu Club 2 jalur dan dari LBS Damai Residance dengan menentukan losses dan drop tegangan terkecil. Gambar single line Etap Penyulang Berawa setelah direkonfigurasi, seperti yang ditunjukan pasda Gambar2.

Skenario Pertama merupakan lokasi pemindahan beban LBS Canggu Club 1 dengan melalui Jalan Batu Sari terhubung Transformato KA 2294, skenario kedua merupakan lokasi pemindahan beban LBS Canggu Club 2 dengan melalui Jalan Baman Beji yang terhubung dengan tranfsformator KA 1692, dan skenario ketiga merupakan lokasi pemindahan beban ketiga pada LBS Damai Residance melalui Jalan Bango yang terhubung ke transformator KA636 pada Penyulang Bumbak yang terdapat pada table 1.
Tabel 1 Tabel Skenario rekonfigurasi Jaringan

\begin{tabular}{|c|c|c|c|c|c|}
\hline No & $\begin{array}{l}\text { Rekonfigurasi } \\
\text { Penyulang }\end{array}$ & $\begin{array}{c}\text { Titik } \\
\text { Perpotongan }\end{array}$ & $\begin{array}{c}\text { Titik } \\
\text { penyambungan }\end{array}$ & $\begin{array}{c}\text { Jalur } \\
\text { Penghantar }\end{array}$ & $\begin{array}{c}\text { Panjang } \\
\text { saluran }\end{array}$ \\
\hline 1 & $\begin{array}{l}\text { Penyulang } \\
\text { Berawa dan } \\
\text { Penyulang } \\
\text { Bumbak }\end{array}$ & $\begin{array}{c}\text { LBS Canggu } \\
\text { Club }\end{array}$ & $\begin{array}{c}\text { KA } 2294 \text { pada } \\
\text { Penyulang } \\
\text { Bumbak }\end{array}$ & $\begin{array}{c}\text { Melaluijalan } \\
\text { Batu Sari }\end{array}$ & $0,6 \mathrm{kms}$ \\
\hline 2 & $\begin{array}{l}\text { Penyulang } \\
\text { Berawa dan } \\
\text { Penyulang } \\
\text { Bumbak }\end{array}$ & $\begin{array}{c}\text { LBS Canggu } \\
\text { Club }\end{array}$ & $\begin{array}{c}\text { KA } 1692 \text { pada } \\
\text { Penyulang } \\
\text { Bumbak }\end{array}$ & $\begin{array}{c}\text { Melalui jalan } \\
\text { Gang Villa } \\
\text { Beji }\end{array}$ & $0,71 \mathrm{kms}$ \\
\hline 3 & $\begin{array}{l}\text { Penyulang } \\
\text { Berawa dan } \\
\text { Penyulang } \\
\text { Bumbak }\end{array}$ & $\begin{array}{l}\text { LBS Damai } \\
\text { Residance }\end{array}$ & $\begin{array}{c}\text { KA 636 pada } \\
\text { Penyulang } \\
\text { Bumbak }\end{array}$ & $\begin{array}{l}\text { Melaluijalan } \\
\text { Gang Bango }\end{array}$ & $0,87 \mathrm{kms}$ \\
\hline
\end{tabular}

Perhitungan losses dan drop tegangan setelah dilakuakan rekonfigurasi dapat dilihat pada rumus (3) dan (4) yang terpasang pada LBS Damai Residance.

Losses Penghantar LBS Damai Residance setelah direkonfigurasi :

$$
\begin{aligned}
\Delta P & =I^{2} x R \\
\Delta P= & I^{2} x \frac{\rho x l}{A} \\
\Delta P & =85^{2} \times \frac{0,03 \times 0,87}{150} \\
\Delta P & =1.25 \mathrm{~kW}
\end{aligned}
$$


Drop tegangan LBS Damai residance

$$
\begin{aligned}
\Delta V & =\mathrm{I} \times(\mathrm{r} \cdot \operatorname{Cos} \theta+\mathrm{x} \cdot \operatorname{Sin} \theta) \times \mathrm{L} \\
\Delta V & =\sqrt{3} \times 167 \times(0,2 \cdot 0,86)+(0) \times 5,16 \\
\Delta V & =289,2 \times 0,185 \times 5 \cdot 16 \\
\Delta V & =244 \mathrm{kVA}
\end{aligned}
$$

\begin{tabular}{|c|c|c|c|c|c|}
\hline \multicolumn{6}{|c|}{ PENYULAVG BUMBAK } \\
\hline & SEBELUM & SESUDAH & $\begin{array}{c}\% \\
\text { SEBELUM }\end{array}$ & $\begin{array}{c}\% \\
\text { SESUDAH }\end{array}$ & KETERANGAN \\
\hline DAYA & $2837 \mathrm{kVA}$ & $5728 \mathrm{kVA}$ & - & - & Meningkat \\
\hline $\begin{array}{l}\text { PANJANG } \\
\text { SALURAN }\end{array}$ & $3,89 \mathrm{kms}$ & $5,16 \mathrm{kms}$ & . & - & Meningkat \\
\hline ARUS & $82 \mathrm{~A}$ & $167 \mathrm{~A}$ & $27,3 \%$ & $55,67 \%$ & Meningkat \\
\hline LOSSES & $5,2 \mathrm{~kW}$ & $28,78 \mathrm{~kW}$ & $0,22 \%$ & $0,62 \%$ & Meningkat \\
\hline $\begin{array}{c}\text { DROP } \\
\text { TEGANGAN }\end{array}$ & $102,2 \mathrm{kVA}$ & $276,1 \mathrm{kVA}$ & $3,6 \%$ & $4,8 \%$ & Meningkat \\
\hline \multicolumn{6}{|c|}{ PENYULANG BERAWA } \\
\hline & SEBELUM & SESUDAH & $\begin{array}{c}\% \\
\text { SEBELUM }\end{array}$ & $\begin{array}{c}\% \\
\text { SESUDAH }\end{array}$ & KETERANGAN \\
\hline DAYA & $8369 \mathrm{kVA}$ & $5428 \mathrm{kVA}$ & - & - & Menurun \\
\hline $\begin{array}{l}\text { PANJANG } \\
\text { SALURAN }\end{array}$ & $10 \mathrm{kms}$ & $7,73 \mathrm{kms}$ & - & - & Menurun \\
\hline ARUS & $242 \mathrm{~A}$ & $157 \mathrm{~A}$ & $80,67 \%$ & $52,3 \%$ & Menurun \\
\hline LOSSES & $117,12 \mathrm{~kW}$ & $38,10 \mathrm{~kW}$ & $1,7 \%$ & $0,7 \%$ & Menurun \\
\hline $\begin{array}{c}\text { DROP } \\
\text { TEGANGAN }\end{array}$ & $775,4 \mathrm{kVA}$ & $387,5 \mathrm{kVA}$ & $9,29 \%$ & $7,13 \%$ & Menurun \\
\hline
\end{tabular}

Tabel 2 data beban setelah di rekonfigurasi

Pemilihan titik perpotongan untuk rekonfigurasi kali ini saya menggunakan lokasi pemindahan bebanpada LBS Damai Residance karena memiliki Losses dan Drop tegangan terkecil dari yang lainnya, dengan losses 1,25 kW dan drop tegangan $1,2 \%(\max 10 \%)$. Arus pembebanan Penyulang Berawa sebelum dilakukan rekonfigurasi sebesar 242 A (81\%) menjadi 157 A $(55,6 \%)$ setelah di rekonfigurasi, Beban Penyulang Bumbak sebelum dilakukan rekonfigurasi sebesar $85 \mathrm{~A}$ $(28,3 \%)$ menjadi 167 A (52,3\%) setelah di rekonfigurasi. Perhitungan losses penghantar sebelum di rekonfigurasi sebesar 5,2 kW (0,22\%), setelah direkonfigurasi pada penyulang Bumbak menjadi 28,78 kW (0,62\%), sedangkan losses pada Penyulang Berawa sebesar $117,1 \mathrm{~kW}(1.7 \%)$ setealah di rekonfigurasi lossesnya menurun menjadi $38,10 \mathrm{~kW}$
(1.1\%)., dengan drop tegangan pada Penyulang Bumbak sebelum di rekonfigurasi sebesar 102,2 kVA (3,6\%), setelah direkonfigurasi meningkat menjadi 244,1 kVA (4,9\%). Drop tegangan pada penyulang Berawa sebelum direkonfigurasi sebesar 775,4 kVA (9,26\%) setelah direkonfigurasi menurun menjadi 494 kVA (7,9\%).

\section{PENUTUP}

\section{A. KESIMPULAN}

Arus pembebanan Penyulang Berawa sebelum dilakukan rekonfigurasi sebesar 242 A (81\%) menjadi 167 A (55,6\%) setelah di rekonfigurasi, Beban Penyulang Bumbak sebelum dilakukan rekonfigurasi sebesar 85 A (28,3\%) menjadi 157 A $(52,3 \%)$ setelah di rekonfigurasi

losses penghantar sebelum di rekonfigurasi sebesar 5,2 kW (0,22\%), setelah direkonfigurasi pada penyulang Bumbak menjadi 28,78 kW (0,62\%), sedangkan losses pada Penyulang Berawa sebesar 117,1 kW (1.7\%) setealah di rekonfigurasi lossesnya menurun menjadi $38,10 \mathrm{~kW}(1.1 \%)$

Drop tegangan pada Penyulang Bumbak sebelum di rekonfigurasi sebesar 102,2 kVA (3,6\%), setelah direkonfigurasi meningkat menjadi 244,1 kVA (4,9\%). Drop tegangan pada penyulang Berawa sebelum direkonfigurasi sebesar 775,4 kVA (9,26\%) setelah direkonfigurasi menurun menjadi 494 kVA $(7,9 \%)$

\section{A. SARAN}

Rekofigurasi harus dilakukan segera mungkin kerena pertumbuhan beban pada penyulang Berawasudah melebihi batas maksimum yang ditentukan, dalam menentukan besar beban yang akan di 
rekonfigurasi harus diketahui perubahan beban dari tahun sebelumnya. Besar beban yang akan direkonfigurasi harus diperhatikan pertumbuhan bebannya, Jalur rekonfigurasi yang dipilih sebaiknya

B. DAFTAR PUSTAKA

[1] PT. PLN (Persero) APD BALI. 2017 Data Penyulang Berawa

[2]Mahendra, Surya. 2015. Studi Rekonfigurasi Jaringan dan Penentuan Lokasi Distributed Generation (DG) Pada Sistem Distribusi 3 Phasa Metode Newthon Rhapson Untuk Meningkatkan Keluaran Daya Aktif DG. Vol. 4, No. 2, ISSN: 2337-3539 (2301-9271 Print).

[3] PT. PLN (Persero). 2010. Standar Kontruksi Jaringan Tegangan Menengah Tenaga Listrik. Jakarta.

[4] F,Iskandar.2015. Studi Pengaruh Rekonfigurasi Jaringan Terhadap Drop Voltage Menggunakan Metode GA Di Bandara Ngurah Rai. E-Journal SPEKTRUM Vol. 2, No. 2.

[5] Hidayah,Nurul. 2015. Analisa Manuver Jaringan Terhadap Keandalan Kontinyuitas Penyaluran Tenaga Listrik Penyulang Ampean. Vol. 3, No. $1: 109-115$

[6] PT. PLN (Persero). 1984. Himpunan buku Petunjuk operasi dan Pemeliharaan peralatan penyaluran tenaga listrik Perusahaan Listrik Umum negara. Jakarta.

[7] Jamaah, Akhmad. 2013. Analisa Beban Section untuk Menentukan Alternatif Manuver Jaringan Distribusi $20 \mathrm{kV}$ Penyulang BRG-3PT PLN (Persero) dilakukan Mengikuti arah dari jalan sehingga nantinya jika terjadi penambahan beban lebih mudah dan tidak ada biaya lahan untuk pemaasangan tiang.

Unit Layanan Salatiga. Vol. 2 No. 3 : $159-158$.

[8] Priadi Hendra, 2015. Evaluasi Untuk Mengatasi Beban Lebih Pada Penyulang Batu Belig. E-Journal SPEKTRUM Vol. 2, No. 1.

[9] Rahmadan, Fahmi. 2015. Analisis Keandalan Pada Penyulang Batu Belig. Vol. 2, No. 2.

[10] Zebua, Osea. 2016. Rekonfigurasi Jaringan Distribusi Untuk Mminimisasi Rugi-rugi pada Penyulang Kabut di gardu Induk Teluk Betung Menggunakan Metode Binary Perticle Swarm Optimization (BPSO). Vol: 5, No. 1, ISSN: 2302 -2949.

[11]Samudra Hery, 2016. Studi Peningkatan Kualitas Pelayanan Penyulang Menggunakan Load Break switch (LBS) Three Way. Teknologi Elektro, Vol. 15, No.1. 